CARTA AL EDITOR

\section{APRENDIZAJE EN TIEMPOS DE AISLAMIENTO SOCIAL: CURSOS MASIVOS ABIERTOS EN LIINEA SOBRE LA COVID-19}

\section{LEARNING IN TIMES OF SOCIAL ISOLATION: MASSIVE OPEN ONLINE COURSES ON COVID-19}

\section{Renatta Quijano-Escate (D) 1,a , Alexis Rebatta-Acuña (D) 1,a, Humberto Garayar-Peceros (iD) 1,a , Katherin Estefany Gutierrez-Flores (iD) 1,a , Guido Bendezu-Quispe (iD) 2,b}

1 Sociedad Científica de Estudiantes de Medicina de Ica, Universidad Nacional San Luis Gonzaga, Ica, Perú.

2 Universidad San Ignacio de Loyola, Vicerrectorado de Investigación, Unidad de Investigación para la Generación y Síntesis de Evidencias en Salud, Lima, Perú.

a Estudiante de Medicina; ${ }^{b}$ médico cirujano, magíster en Informática Biomédica.

Sr. Editor: El Perú es un país afectado por la pandemia de COVID-19, con 11475 casos confirmados y 254 fallecidos hasta el 15 de abril del $2020^{(1)}$. El Gobierno del Perú decretó un estado de emergencia nacional y estableció un régimen de aislamiento social obligatorio para mitigar la trasmisión y el número de casos por la COVID-19, lo cual ha favorecido la respuesta del sistema sanitario frente a esta pandemia ${ }^{(2)}$.

La respuesta de los profesionales de salud frente a la COVID-19 es crucial para controlar la pandemia. Sin embargo, el conocimiento sobre el manejo terapéutico de pacientes con la COVID-19 es limitado; de hecho, no existen aún terapias específicas aprobadas ${ }^{(3)}$. Por otro lado, las medidas tomadas por los gobiernos para mitigar esta enfermedad requieren que la población en general disponga de información sobre la COVID-19, sus medios de trasmisión y la importancia de la participación ciudadana para su control. En este escenario, el uso de la tecnología podría ser útil como herramienta educativa en tiempos de pandemia y aislamiento social, y mitigaría el efecto de la enfermedad a través de programas educativos y la educación continua de los profesionales ${ }^{(4,5)}$.

En los últimos años, los cursos masivos abiertos en línea (MOOC, por sus siglas en inglés) se han convertido en una herramienta educativa útil para trasmitir conocimiento en

Citar como: Quijano-Escate R, Rebatta-Acuña A, Garayar-Peceros H, Gutierrez-Flores KE, Bendezu-Quispe G. Aprendizaje en tiempos de aislamiento social: cursos masivos abiertos en línea sobre la COVID-19. Rev Peru Med Exp Salud Publica. 2020;37(2):375-7. doi: https://doi.org/10.17843/rpmesp.2020.372.5478

Correspondencia: Karla Renatta Quijano Escate; Av. Ayabaca 11004, Ica, Perú; karlaquijanoe@gmail.com

Recibido: 03/04/2020 Aprobado: 22/04/2020 En línea: 24/04/2020 distintas áreas del saber, cuyas fortalezas (no estar limitados a horarios, idioma o ubicación geográfica) permiten que se realicen desde cualquier dispositivo con acceso a internet ${ }^{(6)}$. Se ha descrito previamente el desarrollo de los MOOCs como una respuesta educativa frente a epidemias de enfermedades emergentes y reemergentes ${ }^{(7)}$. Por ello, se realizó una búsqueda manual hasta el 15 de abril del 2020 en plataformas de MOOCs, como Coursera, edX, FutureLearn, XuentangX, Udacity, Miríadax, Alison, Fun.MOOC, UPV[X], Canvas Network, OpenWHO, Formación Alcalá, Open2Study, Class Central y MOOC List, para identificar y conocer las características de MOOCs con contenido sobre la COVID-19. Para la búsqueda, se emplearon los términos COVID-19, SARS$\mathrm{CoV}-2$, coronavirus, Wuhan virus y sus variantes. Adicionalmente, se buscaron MOOCs en portales web y redes sociales de instituciones gubernamentales del Perú.

Se encontraron 28 MOOC sobre la COVID-19, todos con inscripción gratuita. Respecto al público objetivo, 16 cursos se ofrecen para profesionales de la salud, como especialistas en cuidados intensivos y salubristas, y 12 para público general. El promedio de duración es de 14,25 horas (rango: 0,5 a 50). La mayoría de los cursos son en inglés (19), francés y español (7 para ambos). Hay 7 cursos que se ofrecen en español, incluso uno realizado por el Ministerio de Educación del Perú orientado a docentes de colegios e institutos técnicos (actualmente cerrado para inscripciones). La mayor parte de los MOOC han sido desarrollados por instituciones europeas (10) y de la región de las Américas (8) (Tabla 1).

Los hallazgos del estudio describen un rápido desarrollo y oferta de MOOC sobre la COVID-19. Estos cursos los realizan instituciones universitarias y organizaciones reconocidas en todo el mundo, los ofrecen gratuitamente y su público objetivo es la población en general y los profesionales de la salud, como los que realizan atención a pacientes con la COVID-19 en áreas de cuidados críticos. En China, donde se declaró el primer brote de la enfermedad, se tomó la iniciativa de aplicar un sistema de educación en línea a gran escala en reemplazo de los programas originalmente diseñados para modalidad presencial, como una oportunidad de integrar la tecnología y la educación en el contexto del aislamiento ${ }^{(5)}$. Este estudio señalaría que diversas instituciones y organismos en el mundo han visto en los MOOC una oportunidad educativa en línea frente a la COVID-19. Por un lado, encontrar un MOOC de desarrollo local, aunque enfocado a un grupo específico de la población (docentes peruanos), describe un panorama en el que se reconoce la utilidad de la educación en línea respecto a un problema de salud. Por otro lado, que la mayor parte de los MOOC no se impartan en español podría ser una limitación para su uso como herramienta educativa sobre la COVID-19 tanto en población general como para profesionales de la salud en Perú. 
Tabla 1. Cursos masivos abiertos en línea (MOOC) gratuitos y disponibles sobre la COVID-19

\begin{tabular}{|c|c|c|c|c|c|}
\hline Plataforma & Título en español & Institución (país) & $\begin{array}{c}\text { Idiomas } \\
\text { disponibles }\end{array}$ & $\begin{array}{c}\text { Duración } \\
\text { (horas) }\end{array}$ & Audiencia \\
\hline Alison & Coronavirus: Lo que necesitas saber & ALISON & Inglés & 2 & Público en general \\
\hline \multirow{6}{*}{ Coursera } & $\begin{array}{l}\text { Control mental: gestión de su salud mental } \\
\text { durante COVID-19 }\end{array}$ & University of Toronto (Canadá) & Inglés & 10 & Público en general \\
\hline & $\begin{array}{l}\text { Combatiendo COVID-19 con } \\
\text { Epidemiología: una enseñanza de Johns } \\
\text { Hopkins }\end{array}$ & $\begin{array}{l}\text { Johns Hopkins University } \\
\text { (EE. UU.) }\end{array}$ & Inglés & 5 & Público en general \\
\hline & $\begin{array}{l}\text { COVID-19: Lo que necesitas saber } \\
\text { (Elegible para CME) }\end{array}$ & IPMA+Osmosis & Inglés & 2 & Personal de salud \\
\hline & $\begin{array}{l}\text { La ciencia importa: Hablemos de } \\
\text { COVID-19 }\end{array}$ & $\begin{array}{l}\text { Imperial College London (Reino } \\
\text { Unido) }\end{array}$ & Inglés & 19 & Público en general \\
\hline & COVID-19: Una Actualización Clínica & University of Florida (EE. UU.) & Inglés & 6 & Personal de salud \\
\hline & Epidemias & $\begin{array}{l}\text { Universidad de Hong Kong } \\
\text { (China) }\end{array}$ & Inglés, chino (tradicional) & 11 & Público en general \\
\hline \multirow{5}{*}{ edX } & $\begin{array}{l}\text { Cursos para profesionales de la Salud } \\
\text { Pandemia COVID } 19\end{array}$ & $\begin{array}{l}\text { Pontficia Universidad Javeriana } \\
\text { (Colombia) }\end{array}$ & Español & 6 & $\begin{array}{l}\text { Médicos no } \\
\text { intensivistas }\end{array}$ \\
\hline & Epidemias II & $\begin{array}{l}\text { The University of Hong Kong } \\
\text { (China) }\end{array}$ & Inglés, chino & 6 & Público en general \\
\hline & $\begin{array}{l}\text { COVID - 19: Ventilación mecánica para no } \\
\text { intensivistas }\end{array}$ & $\begin{array}{l}\text { Pontificia Universidad Javeriana } \\
\text { (Colombia) }\end{array}$ & Español & 6 & Personal de salud \\
\hline & $\begin{array}{l}\text { COVID - 19: Abordaje inicial del paciente } \\
\text { con infección por Covid-19 }\end{array}$ & $\begin{array}{l}\text { Pontificia Universidad Javeriana } \\
\text { (Colombia) }\end{array}$ & Español & 3 & Personal de salud \\
\hline & Ventilación Mecánica para COVID-19 & Harvard University (EE. UU.) & Inglés & 2 & Personal de salud \\
\hline $\begin{array}{l}\text { Formación } \\
\text { Alcalá }\end{array}$ & $\begin{array}{l}\text { Curso de prevención y control de } \\
\text { infecciones causadas por el coronavirus } \\
\text { (COVID-19) }\end{array}$ & Universidad San Jorge (España) & Español & 50 & Personal de salud \\
\hline \multirow{4}{*}{ Fun.MOOC } & COVID-19 y cuidados críticos & $\begin{array}{l}\text { Université Paris-Est Créteil } \\
\text { (UPEC) (Francia) }\end{array}$ & Francés & 2 & $\begin{array}{l}\text { Personal médico } \\
\text { y profesionales en } \\
\text { ventilación artificial }\end{array}$ \\
\hline & Ventilación artificial: nivel avanzado & UPEC (Francia) & Francés & 10 & $\begin{array}{l}\text { Personal médico de } \\
\text { cuidados intensivos }\end{array}$ \\
\hline & Virus emergentes y reemergentes & Institut Pasteur (Francia) & Inglés & 2 & Público en general \\
\hline & COVID-19 y cuidados críticos & $\begin{array}{l}\text { University Paris-Est Créteil } \\
\text { (Francia) }\end{array}$ & Francés & 2 & Público en general \\
\hline \multirow{4}{*}{ FutureLearn } & COVID-19: Abordar el nuevo coronavirus & $\begin{array}{l}\text { London School of Hygiene \& } \\
\text { Tropical Medicine } \\
\text { (Reino Unido) }\end{array}$ & Inglés & 12 & Público en general \\
\hline & Gestión de COVID-19 en la práctica general & $\begin{array}{l}\text { St. George's, University of } \\
\text { London (Reino Unido) }\end{array}$ & Inglés & 4 & Personal de salud \\
\hline & Diagnóstico y pruebas de COVID-19 & $\begin{array}{l}\text { London School of Hygiene \& } \\
\text { Tropical Medicine } \\
\text { (Reino Unido) }\end{array}$ & Inglés & 9 & $\begin{array}{l}\text { Personal de salud } \\
\text { encargado de pruebas } \\
\text { diagnósticas }\end{array}$ \\
\hline & $\begin{array}{l}\text { Cuidados críticos COVID-19: comprensión } \\
\text { y aplicación }\end{array}$ & $\begin{array}{l}\text { The University of Edinburgh; } \\
\text { Royal College of Physicians of } \\
\text { Edinburgh (Reino Unido) }\end{array}$ & Inglés & 6 & $\begin{array}{l}\text { Personal clínico de } \\
\text { primera línea contra la } \\
\text { COVID-19 }\end{array}$ \\
\hline \multirow{6}{*}{ OpenWHO } & $\begin{array}{l}\text { Diseño de instalaciones de tratamiento de } \\
\text { infección respiratoria aguda grave (IRAG) }\end{array}$ & $\begin{array}{l}\text { Organización Mundial de la } \\
\text { Salud }\end{array}$ & Inglés & 1 & Personal de salud \\
\hline & $\begin{array}{l}\text { COVID-19: Pautas de planificación } \\
\text { operativa y plataforma de socios COVID-19 } \\
\text { para apoyar la preparación y respuesta del } \\
\text { país }\end{array}$ & $\begin{array}{l}\text { Organización Mundial de la } \\
\text { Salud }\end{array}$ & Inglés, portugués, francés. & 2 & Público en general \\
\hline & $\begin{array}{l}\text { Prevención y control de nuevas infecciones } \\
\text { por coronavirus (COVID-19) }\end{array}$ & $\begin{array}{l}\text { Organización Mundial de la } \\
\text { Salud }\end{array}$ & $\begin{array}{l}\text { Español, inglés, ruso, portugués, } \\
\text { chino, francés, japonés, indonesio, } \\
\text { serbio, macedonio, italiano. }\end{array}$ & 1 & Personal de salud \\
\hline & $\begin{array}{l}\text { Nuevos virus respiratorios, incluido } \\
\text { el COVID-19: métodos de detección, } \\
\text { prevención, respuesta y control }\end{array}$ & $\begin{array}{l}\text { Organización Mundial de la } \\
\text { Salud }\end{array}$ & $\begin{array}{l}\text { Español, ruso, turco, macedonio, } \\
\text { árabe, serbio, hindú, persa, francés, } \\
\text { portugués, inglés. }\end{array}$ & 3 & $\begin{array}{l}\text { Profesionales de la salud } \\
\text { pública, gerentes de } \\
\text { incidentes, personal }\end{array}$ \\
\hline & $\begin{array}{l}\text { Introducción al video COVID-19 en } \\
\text { lenguaje de señas indio }\end{array}$ & $\begin{array}{l}\text { Organización Mundial de la } \\
\text { Salud }\end{array}$ & Inglés & 0,5 & $\begin{array}{l}\text { Personas con } \\
\text { discapacidad }\end{array}$ \\
\hline & Infecciones respiratorias ePROTECT (FR) & $\begin{array}{l}\text { Organización Mundial de la } \\
\text { Salud }\end{array}$ & $\begin{array}{l}\text { Inglés, francés, indonesio, ruso, } \\
\text { portugués, chino. }\end{array}$ & 2 & $\begin{array}{l}\text { Equipo de salud } \\
\text { responsable de atención } \\
\text { de la COVID-19. }\end{array}$ \\
\hline PerúEduca & Actuando frente al Coronavirus COVID-19 & Ministerio de Educación (Perú) & Español & 15 & Docentes \\
\hline
\end{tabular}


En conclusión, se han desarrollado MOOC referentes a la COVID-19 y han sido puestos a disposición del personal de salud y público en general. La baja oferta de cursos en español limitaría su utilidad en la población peruana. Si bien el uso de los MOOC depende de la disponibilidad de acceso a internet y del grado de alfabetización digital de la población, en el Perú se ha experimentado una creciente disminución de la brecha tecnológica, lo que indica que cada vez hay más peruanos que tienen acceso a internet y están más familiarizados con el uso de nuevas tecnologías. Por ello, las herramientas educativas en línea como los MOOC son alternativas viables para la educación de los profesionales de la salud y población en general, durante el aislamiento social.

Contribuciones de los autores: GBQ participó en la concepción del artículo y asesoría técnica. GBQ y RQE participaron en la interpretación y revisión crítica del artículo. Todos los autores participaron en la recolección de datos, redacción y aprobación de la versión final.

Fuente de financiamiento: Autofinanciado.

Conflictos de interés: Los autores declaran no tener conflictos de interés.

\section{REFERENCIAS BIBLIOGRÁFICAS}

1. Ministerio de Salud. Sala situacional COVID-19 Perú [Internet]. Lima: MINSA; 2020 [citado el 2 de abril de 2020]. Disponible en: https:// covid19.minsa.gob.pe.
2. Decreto Supremo que declara Estado de Emergencia Nacional por las graves circunstancias que afectan la vida de la Nación a consecuencia del brote del COVID-19. Decreto supremo No 044-2020-PCM del 15 de marzo de 2020 El Peruano (15-03-2020) [citado el 2 de abril de 2020]. Disponible en: https://busquedas.elperuano.pe/normaslegales/ decreto-supremo-que-declara-estado-de-emergencia-nacional-po-decreto-supremo-n-044-2020-pcm-1864948-2/.

3. World Health Organization. Clinical management of severe acute respiratory infection when COVID-19 is suspected. Interim guidance [Internet]. Ginebra: WHO; 2020 [citado el 15 de abril de 2020]. Disponible en: https://www.who.int/docs/default-source/coronaviruse/ clinical-management-of-novel-cov.pdf.

4. Valdez-García JE, López Cabrera MV, Jiménez Martínez MA, Díaz Elizondo JA, Dávila Rivas JAG, Olivares Olivares SL. Me preparo para ayudar: respuesta de escuelas de medicina y ciencias de la salud ante COVID-19. Inv Ed Med. 2020;9(35):1-11. doi: 10.22201/facmed.20075057e.2020.35.20230.

5. Zhou L, Wu S, Zhou M, Li F. 'School's Out, But Class' On', The Largest Online Education in the World Today: Taking China's Practical Exploration During The COVID-19 Epidemic Prevention and Control As an Example. Best Evid Chin Edu. 2020;4(2):501-519. doi: 10.2139/ ssrn. 3555520 .

6. Liyanagunawardena TR, Williams SA. Massive Open Online Courses on Health and Medicine: Review. J Med Internet Res. 2014;16(8):e191. doi: 10.2196/jmir.3439.

7. Bendezu-Quispe G, Torres-Roman JS, Salinas-Ochoa B, Hernández-Vásquez A. Utility of massive open online courses (MOOCs) concerning outbreaks of emerging and reemerging diseases. F1000Research. 2017;6:1699. doi: 10.12688/f1000research.12639.2. 